\title{
Psicoterapia e Religião: Construção de Sentido e Experiência do Sagrado ${ }^{1}$
}

\author{
Maurício da Silva Neubern \\ Universidade de Brasília
}

\begin{abstract}
RESUMO
O presente trabalho procura destacar que a construção de sentido subjetivo é de grande importância em psicoterapia para a compreensão da experiência de sagrado do sujeito. Ao mesmo tempo, ressalta que a construção do sentido subjetivo está ligada ao reconhecimento da especificidade da experiência religiosa como um campo que não deve ser reduzido a outro campo do saber, como ocorre tradicionalmente em diferentes modelos de ciência e de abordagens psicoterápicas. Por meio de uma ilustração clínica, ressalta que a compreensão do sentido subjetivo é fundamental para as possibilidades do diálogo no processo psicoterápico, como da construção do contexto terapêutico que qualifique os recursos do sujeito. $\mathrm{O}$ trabalho é concluído destacando a fecundidade da experiência do sagrado na construção de sentidos subjetivos, o diálogo como condição de acesso ao mundo do outro e as possibilidades técnicas das quais o sujeito dispõe, a partir de seu sistema de crenças e práticas sociais, para lidar com suas próprias demandas.
\end{abstract}

Palavras-chave: sentido subjetivo; religião; psicoterapia.

\section{ABSTRACT \\ Psychotherapy and Religion: \\ Construction of Subjective Sense and the Experience of the Sacred}

The purpose of this paper is to demonstrate that the construction of subjective sense is highly significant in understanding the sacred experiences in psychotherapy. The paper also underlines the construction of sense as a way to recognize religious experience as a specific field that should not be reduced to other fields of knowledge, as is traditionally done in many scientific models and psychotherapy approaches. A clinical example is used to illustrate how understanding subjective sense is essential in generating dialogue possibilities during psychotherapy, and for creating a therapeutic context that qualifies the coping mechanisms of the subject. The paper concludes by emphasizing that religious experience is especially productive in constructing subjective senses, that dialogue is a way to access the world of others, and that belief systems and social practices are technical possibilities that enable subjects to deal with their own necessities.

Keywords: subjective sense; religion; psychotherapy.

Pode-se considerar que a prática psicoterápica atual, em boa parte inspirada pela modernidade (Santos, 2000), possui duas grandes características marcantes no que se refere à experiência religiosa ${ }^{2}$ dos sujeitos. Por um lado, é comum que as construções de sentido desenvolvidas pelos mesmos sejam, de alguma forma, abafadas ou excluídas diante de alguma teoria consagrada, uma vez que esta faz referência a algum campo já colonizado e pretensamente conhecido pela racionalidade científica. Assim, o que para um sujeito se configura como "a comunicação com o mundo espiritual", para os psicoterapeutas pode ser a manifestação de alguma potência inconsciente (Mijolla, 1981), um transtorno dissociativo ou personalidade múltipla (Hacking, 2001), ou ainda a expressão de determinado discurso numa rede social específica (Cerqueira-Santos, Koller \& Pereira, 2004). Da mesma forma que ocorre com outras demandas (Gergen \& Kaye, 1998; Neubern, 2005), a experiência religiosa do sujeito é substituída por alguma noção central do sistema teórico do psicólogo ou terapeuta que passa a gerar sentidos para este em detrimento do que ela, de fato, significa para seus próprios protagonistas. Sob a chancela de noções individualistas, naturalistas, patológicas e deterministas, a construção de sentidos própria ao sujeito é descaracterizada e, em consequência, permanece desconhecida. 
Do outro lado da moeda, essa tendência reducionista implica no não reconhecimento do estatuto ontológico próprio da experiência religiosa, isto é, de um campo específico e com características próprias que não se reduz a outras dimensões, sejam elas psicológicas, sociais ou culturais, apesar de possuir estreitas relações com elas (Carvalho, 1994). Para explicar uma experiência dessa ordem, os psicólogos e seus colegas de ciência, frequentemente, recorrem a um outro campo, como os genes e o cérebro (Rose, 2006), a mitologia (Nathan, 1999), a linguagem (Quintana, 1999) ou a um desejo transcendente (Freud, 1927/1997), sem buscarem uma compreensão do campo religioso em si, com suas características próprias. Na perspectiva deste trabalho, embora a religião possua práticas e relações sociais numa comunidade ou instituição que comungam um sistema de crenças, o que a define como campo subjetivo distinto é a experiência do sagrado (Otto, 1917/2007), isto é, aquilo que é definido por uma tradição e pelo sujeito como divino, que se refere a uma experiência subjetiva que não se apreende pelas palavras, mas permanece na esfera do indizível no seio de um sistema de crenças ou de uma cultura. Embora se situe numa esfera profundamente ligada ao emocional (James, 1902/1987), essa experiência pode gerar significados e sentidos, mas permanece inesgotada por eles, de maneira que caso fosse absorvida ou definida por palavras ela simplesmente deixaria de existir.

$\mathrm{Na}$ maioria das vezes temporária ${ }^{3}$, ela não se restringe à ética nem à moral, apesar das relações com elas, e comumente resulta em sensações descritas em termos de paz, totalidade e plenitude, que colocam o sujeito numa perspectiva diferenciada de compreensão do tempo, do espaço e de seu destino, numa felicidade e prazer corporal que parecem romper com as circunstâncias atuais (Eliade, 1965). Também é comum preconize a comunhão com um poder espiritual superior que está na origem das coisas e do mundo e, além das limitações típicas do mundo humano, oferece ao sujeito uma possibilidade distinta de compreender temas existenciais recorrentes na vida das pessoas, como o sofrimento, a vida, a morte, o trabalho e o outro (Eliade, 1969; Otto, 1917/2007). Não é sem razões que sua ocorrência esteja ligada a processos de conversão religiosa ou mudanças radicais de vida (James, 1902/1987).

Nesse sentido, vale destacar que não é raro que a experiência religiosa tenha marcado as relações terapêuticas por meio de uma considerável distância entre seus protagonistas. A persistente tendência de traduzir o que se passa com o outro sem o devido acolhimento costuma colocar os psicoterapeutas longe do que seria coerente para a busca de um diálogo produtivo em termos de mudança. Como os psicoterapeutas não reconhecem a experiência dos sujeitos como um campo que não se reduz a seus aportes teóricos, torna-se difícil um entendimento mais amplo sobre a mesma, sobre as realidades que constrói no cotidiano de seus clientes, sobre os personagens que a habitam e como ocupam suas posições, sobre o que é o contato com o sagrado e, numa palavra, sobre as possibilidades de sentido que dela decorrem. Desse modo, mesmo tendências promissoras, como as trazidas por Lax (1997) e Anderson (1997) podem ser comprometidas, uma vez que as possibilidades de conversação e diálogo podem ser significativamente restritas caso não se reconheça a existência da experiência religiosa como um campo específico de subjetivação. Vale questionar até que ponto poderia seguir uma conversação com um sujeito, caso no diálogo consigo mesmo (Andersen, 1996), o terapeuta permanecesse aferrado a alguma concepção dominante do pensamento moderno, onde a religião é uma ilusão ou subproduto de algum campo já colonizado.

Diante do exposto, o objetivo do presente trabalho é o de destacar que a construção de sentido subjetivo ${ }^{4}$ (Gonzalez Rey, 2005, 2007) é de grande importância para a compreensão da experiência do sagrado (Otto, 1917/2007) em psicoterapia, uma vez que não a reduz a algum campo prévio do conhecimento, mas procura compreender como o sujeito vivencia essa experiência em termos simbólicos e emocionais. Sem guardar a pretensão de buscar explicar a experiência do sagrado, levanta-se aqui a possibilidade de estabelecer um diálogo sobre temas que, com frequência, permanecem em silêncio na relação terapêutica, malgrado sua importância na vida dos clientes, como a comunicação com o mundo espiritual, o impacto desses contatos, os seres com quem interage, as mensagens que são transmitidas. Ao mesmo tempo, busca-se mostrar que o sentido subjetivo na experiência religiosa também se mostra pertinente por agregar de forma complexa (Neubern, 2004) a subjetivação de processos sociais, históricos, culturais, institucionais, que também perpassam essa experiência. Essa discussão será desenvolvida por meio de uma breve ilustração clínica de uma jovem que solicitou ajuda para problemas mediúnicos e psicológicos.

\section{Mariana, 30 anos}

Mariana chegou ao consultório do autor, queixando-se de várias coisas. Dizia-se deprimida e alegava precisar muito de ajuda, mas tinha receio de não ser 
compreendida, pois suas relações terapêuticas anteriores haviam falhado. Seus terapeutas não respeitavam suas crenças. Afirmava também ter problemas com sua mediunidade, pois era uma porta que a deixava mais vulnerável e sensível ao sofrimento. Além disso, havia desenvolvido uma compulsão sexual muito intensa que lhe trazia considerável sofrimento, principalmente devido a recentes experiências homossexuais. Sendo a filha mais jovem de 4 irmãos, Mariana sentiase por vezes inferiorizada em sua família, já que sua pele era mais morena do que a dos demais, que eram bem claros e com olhos verdes. Porém, sua mediunidade lhe colocava num papel de destaque em suas redes sociais, principalmente em seu centro espírita, onde se considerava que possuía uma missão a realizar com esse dom. Divorciada há pouco tempo, tinha uma filha de cinco anos e preocupava-se muito com os exemplos que daria para ela.

\section{Diálogo e Sentido}

Logo que chegou ao consultório, Mariana se colocou da seguinte forma:

Vim até você porque acho que você pode me entender e porque também preciso muito de ajuda. Minhas outras tentativas de terapia foram fracassadas. Numa delas, o sujeito ficava me mandando fazer agendas, tarefinhas e anotar coisas; noutra, ele queria me doutrinar, porque também era espírita; $e$ numa terceira vez, ele não me entendia, pois dizia que Frei Giuseppe era uma imagem de meu inconsciente - o arquétipo do sábio. Pra mim, ele é uma pessoa como eu ou você, só que sem o corpo físico. Então, como vi sua palestra, acho que você pode realmente entender o que acontece comigo. Você me pareceu ter sensibilidade com o tema, respeito com ele.

$\mathrm{O}$ trecho acima remete à problemática sobre as possibilidades do diálogo que tem sido, nas últimas décadas, um tema recorrente nas reflexões sobre as relações humanas no contexto clínico, particularmente, na psicoterapia. Em termos gerais, a crítica de diferentes autores (Anderson, 1997; Anderson \& Goolishian, 1998; Gergen \& Kaye, 1998; Gonzalez Rey, 2007; Neubern, 2004) reside na tendência que os terapeutas possuem de reduzir as construções de seus clientes a categorias e esquemas teóricos a priori de alguma teoria consagrada pela comunidade científica. A perspectiva, inspirada pelo ímpeto moderno, de um conhecimento mais legítimo e, por vezes, mais verdadeiro ou confiável que os outros, acaba levando o psicoterapeuta a desprezar as outras formas de narrativa sobre o mundo de maneira a reduzi-las a um campo em que ele mesmo é o especialista e o cliente pouco tem a colaborar. Essa hierarquia respaldada por uma pretensa superioridade narrativa, com muita frequência, traduz as narrativas dos clientes que se referem a temáticas religiosas em processos inconscientes, sexuais e edípicos, em processos neurofisiológicos, em transtornos e quadros de psicopatologia, em relações de poder no jogo social ou em esquemas cognitivos que, de um modo geral, pouco possuem do teor espiritual que seus protagonistas lhe atribuem ${ }^{5}$.

O relato de Mariana traz, numa perspectiva clínica, o tema da incompreensão caracterizada por barreiras que inviabilizaram por várias vezes relações terapêuticas produtivas. Para ela era de considerável importância que suas perspectivas fossem acolhidas, que seu pensamento fosse compreendido e suas crenças respeitadas, o que de fato não ocorreu, pois ela percebia que seus psicoterapeutas não a escutavam, mas buscavam engajá-la em certas práticas terapêuticas sem demonstrar interesse em suas narrativas ou sutilmente lhe ofereciam uma forma mais científica de compreender seu problema. Aqui se esbarra necessariamente no problema do sentido subjetivo e de sua importância primordial para os processos terapêuticos que envolvem demandas ligadas a experiências religiosas. Desse modo, é importante que a compreensão do sentido subjetivo não envolva apenas uma concepção teórica, mas também uma disposição subjetiva do psicoterapeuta para permitir sua emergência na relação com o cliente.

Um dos primeiros pontos que se destaca nessa perspectiva é a necessidade de um autoquestionamento por parte do psicoterapeuta, inclusive quando se deparar com crenças diferentes das suas sobre a vida, a existência e o mundo ou, simplesmente, sobre religião. É difícil para um psicoterapeuta colocar-se disponível para compreender o outro, se ele está por demais aferrado a suas próprias teorias, concebendoas como narrativas exclusivas de entendimento dos temas trazidos (Andersen, 1996). Ao mesmo tempo, ele não pode abandonar de todo suas concepções teóricas porque é a partir delas que determinados processos nascem durante uma relação terapêutica. Esse dilema existente entre necessidades aparentemente antagônicas o coloca na condição de ser duplo para exercer seu métier. Por um lado, notadamente quando em relação com o sujeito, é necessário que ele mergulhe no cenário do outro, que se deixe invadir por ele, procurando compreende-lo a partir das próprias perspectivas deste cenário. Para Mariana, Frei Giuseppe 
era um espírito protetor e não uma imago ou uma alucinação, sendo importante que ele fosse visto dessa forma. Nessa postura, a pressa em concluir geralmente não é bem vinda, pois o psicoterapeuta deve sempre estar interessado em saber um pouco mais, ou seja, em buscar acessar quais realidades são geradas a partir dessa figura, que impactos possui em sua vida, em sua relação com o sagrado, com os outros, enfim, que sentidos são criados a partir da relação entre ela e a cliente. Estar disponível para um entendimento sincero e interessado do outro, considerar o que diz como algo importante de ser considerado e compreender que aquela é a realidade construída pelo sujeito, são algumas das atitudes com que o psicoterapeuta deve adentrar o contexto do diálogo (Andersen, 1997; Anderson \& Goolishian, 1998). Assim, quando o autor se interessou em saber quem era Frei Giuseppe e o que ele dizia sobre a cliente, como sobre a própria terapia, ou seja, quando o reconheceu de acordo com as crenças e os sentidos da própria cliente, foi possível perceber um estreitamento mais intenso do vínculo na relação terapêutica, uma sensação de cumplicidade que era partilhada e reconhecida entre essas duas pessoas que se reuniam para discutir sobre temas tão delicados quanto importantes. Daí talvez viesse a ideia de sensibilidade e respeito esperados por Mariana para uma boa relação terapêutica.

Por outro lado, para que possa teorizar, cabe ao psicoterapeuta refletir profundamente sobre o papel da teoria diante dessa prática, o que nem sempre consiste em tarefa fácil, uma vez que exige uma habilidade - o saber pensar (Demo, 2000) - que nem sempre é fácil de adquirir. Assim, mesmo que considerasse o espírito protetor de Mariana como uma imago, sua construção teórica deveria se voltar para a complexa articulação de processos subjetivos presentes na relação com esta figura, visando compreender como as crenças se articulavam com seus processos emocionais tanto em sua história, como em sua ação social (Gonzalez Rey, 2007). A construção de sentido em torno de Frei Giuseppe aparecia para Mariana passa, portanto, pela integração subjetiva de processos e acontecimentos sociais e familiares (Anderson \& Goolishian, 1998; Gonzalez Rey, 2005), pelo seu sistema de crenças (Morin, 1991; Neubern, 2004) e pela própria participação enquanto um personagem ativo em sua vida (Morin, 1994): ele aparecia para Mariana desde a infância, em momentos difíceis ou prazerosos e sempre se colocava no papel de alguém que cuida, protege e aconselha. Através de suas intervenções em transes mediúnicos ou sonhos, ela pôde ter uma compreensão de suas vidas passadas onde apareciam pessoas significativas do hoje e acontecimentos muito ligados para ela com sua situação atual. E, apesar de não se manifestar com frequência, ele costumava lhe aparecer nos momentos mais cruciais e importantes, como suas crises mediúnicas, seu casamento, sua formatura e o nascimento de sua filha.

Desse modo, esboçando uma breve compreensão sobre a construção de sentido dessa figura para Mariana, é possível considerar que Frei Giuseppe era uma figura superior, dentro de suas crenças espíritas, ligada profundamente à experiência do sagrado, e, ao mesmo tempo, alguém que desempenhava um papel paternal e de cuidado. Ela mesma considerava que, como seu pai terreno era problemático e ausente, precisava da figura de seu mentor para que pudesse obter apoio e compreensão em situações importantes de vida. Além disso, era ele quem lhe abria as portas de algo muito importante para ela - o mundo espiritual colocando-se como um guia que a orientaria e instruiria nesse complexo universo. Suas intervenções mágicas abriam-lhe ainda a perspectiva de associar uma crença de sua religião - as vidas passadas - com seu mundo atual, em seus personagens, relações e acontecimentos. Em suma, tratava-se de uma figura central em sua vida, uma pessoa que ocupava o lugar de cuidador, orientador, sábio, pai e porta para o mundo espiritual, o lugar de alguém que a conhece há muitos séculos, o que trazia emoções de intimidade, gratidão, amor, afeto e dever. Não é sem razões que seus conflitos fossem muito intensos já que suas condutas sexuais no momento pareciam confrontar os sentidos ligados a esse mentor em sua vida, de maneira que, nos momentos mais críticos, Frei Giuseppe passava a significar seu fracasso e ruína frente à sua missão espiritual.

O que tal perspectiva aponta é a importância de que a teoria busque oferecer condições para articular as várias facetas de processos que compõem a construção de sentidos subjetivos do sujeito (Gonzalez Rey, 2007). Na posição aqui adotada essa meta é muito mais interessante do que procurar descrever os padrões e mecanismos da experiência sagrada. Porém, em termos de psicoterapia, deve-se estar atento à forma como as teorias são subjetivadas na relação, pois o papel fundamental da teoria, nesses casos, não é o de bastar a si mesma, mas a de servir como referência para que o processo terapêutico se aprofunde e se desenvolva. Se a teoria ocupa o lugar semelhante ao de pano de fundo, e não o de um patamar último para o qual devem ser transpostas as informações do mundo empírico, torna-se possível a tarefa do terapeuta de 
compreender as várias articulações presentes na construção de sentido do cliente. O que surge diante dele é o cliente com a riqueza de seu universo subjetivo e não a obrigação de obedecer a uma entidade reificada, de modo a favorecer a construção de um vínculo no qual o acesso ao outro seja possível.

No entanto, é importante ressaltar que essa aceitação do outro traz também à tona a necessidade de um processo reflexivo por parte do psicoterapeuta, principalmente devido ao impacto que as temáticas ligadas à religião costumam trazer. É perfeitamente possível que o psicoterapeuta sinta incômodos, crie preconceitos, rejeite seu cliente e se angustie na relação com ele, até mesmo porque sua formação, perpassada pela batalha histórica entre ciência e religião, nem sempre o prepara adequadamente para lidar com tais circunstâncias. Contudo, tais processos devem ser concebidos como integrantes a bem dizer "orgânicos" da relação humana e revertidos a favor da continuidade do diálogo por meio de processos reflexivos que transformem o incômodo na possibilidade de perguntar e entender o outro (Andersen, 1996; Anderson \& Goolishian, 1998). O problema, assim, não é o de ter ou não preconceitos, mas o de saber quais são os preconceitos e como eles podem ser utilizados para criar novas perguntas e manter o respeito e a consideração típicos do contexto de diálogo. Isso leva, fatalmente, o psicoterapeuta a uma transformação uma vez que não são apenas as ideias, emoções e significados dos clientes que se modificam num processo relacional dessa natureza. Afinal, não é pelo apego dogmático a suas próprias ideias que a relação terapêutica cumpre seus objetivos, mas pela adoção de uma postura que permita a possibilidade de que elas se modifiquem.

\section{Experiência do Sagrado}

Em certa ocasião, Mariana relatou uma experiência com seu mentor nos seguintes termos:

Teve uma vez que eu estava muito mal, muito deprimida mesmo com tudo isso. Eu tinha vergonha do Frei Giuseppe, porque ele sabe dessa minha situação. Mas eu dei o braço a torcer e chamei por ele (...) fiz uma prece fervorosa e chamei por ele. Ele apareceu e acariciou meus cabelos (...) tinha um sorriso lindo, paternal (...) ele nunca me julgou. Senti uma espécie de paz muito grande, que poucas vezes eu senti. Tudo isso parecia ficar pequeno, com pouca importância (...) é como se eu parasse de me debater na lama e alguém me elevasse lá pra cima e dissesse: 'olha só como tudo isso é pequeno'. Senti algo tão bom, tão pleno, tão paz que peguei num sono profundo e suave, depois de três noites sem conseguir dormir direito.
Boa parte do discutido até aqui é aplicável às diversas demandas de psicoterapia de um modo geral, sem que haja uma necessidade específica de discutir mais a fundo o que leva uma pessoa a buscar ajuda. No que se refere à religião, é importante destacar que a construção de sentido é, antes de tudo, complexa, pois pode ser perpassada por várias dimensões ao mesmo tempo (Neubern, 2004). Com Mariana, por exemplo, os sentidos sobre a mediunidade se revestiam de vários processos, pois lhe conferiam um poder diante da fragilidade com que visualizava sua própria imagem; uma condição especial diante de seu sentimento de inferioridade (devido principalmente à cor de sua pele); e uma possibilidade de inserção na rede social privilegiada, pois todos recorriam a ela atrás de alguma orientação, cuidado ou benefício. Suas reminiscências de vidas passadas lhe davam mesmo uma explicação sobre sua vida, inclusive sobre suas principais dificuldades de relacionamento familiar: seus problemas sexuais desde a infância referiam-se a seu passado na França, onde havia desencaminhado sexualmente muitos jovens. Isso lhe permitia uma compreensão particular e lógica da vida atual, onde localizava seus antigos comparsas (agora como seu pai e seus irmãos), como também lhe permitia conceber que a mediunidade lhe conferia novamente uma condição de poder que, desta vez, deveria ser utilizada para encaminhar as pessoas ao bem ${ }^{6}$.

O trecho acima relatado por Mariana é bastante significativo no que se refere à construção de sentido e como a experiência do sagrado, ao mesmo tempo em que colaborou para seus conflitos, oferecem também possibilidades para configurá-los de outra forma. No momento em que relatou essa passagem, ela ainda estava numa situação caracterizada por uma separação bastante acentuada entre duas facetas importantes de sua vida: por um lado, estava a vida aceita socialmente, marcada por uma imagem de mãe, profissional e médium possuidora de uma missão no espiritismo; por outro, estava sua vida sexual atribulada, escondida e marginal, com várias práticas reprováveis por suas crenças e sua rede social. Na presença de qualquer personagem pertencente ao mundo aceito, o sentido dominante era o de vergonha e humilhação, como ela mesma relatou diante da figura de seu mentor espiritual, de modo que, mesmo que tal figura não fizesse qualquer menção em julgá-la, Mariana se sentia condenada diante de seu olhar. Como o impasse não se resolvia conforme suas expectativas, em termos de poder viver apenas um desses lados, seu sofrimento era intenso e, em suas reflexões nos seus momentos mais introspectivos, seu 
problema adquiria sentido de algo insolúvel, de uma situação inteiramente sem saída.

No entanto, atingindo um ponto crítico desse sofrimento, Mariana resolve apelar para um recurso típico de sua religião - a prece - clamando para uma figura de proteção, de quem sentia acentuada vergonha - seu mentor. Tal prática, que evocou uma experiência do sagrado, proporcionou-lhe uma perspectiva distinta, trazendo-lhe a sensação de ser tirada do meio do conflito insolúvel para ser colocada num ângulo que lhe abria possibilidade de conferir uma intensidade emocional diferente aos dilemas em que vivia. $\mathrm{O}$ impacto de semelhante experiência foi considerável de várias maneiras em termos de suas construções de sentido sobre sua situação. A princípio, o deslocamento espacial parece sugerir-lhe a ideia de que o problema pode, de fato, ser visto de outra forma, isto é, de uma perspectiva mais alta (espiritual) que a ajude a conferir valor em sua vida ao que realmente merece. Como ela parece ir para um lugar distinto, há também uma consequência temporal em que sua situação parece não ser insolúvel neste momento, mas poderá vir a sê-lo no futuro. Em seguida, há a ideia de que aquela figura de quem tinha vergonha é quem lhe propicia essas possibilidades, o que abre a perspectiva de que esse recurso seja utilizado outras vezes. Em suma, a experiência do sagrado, embora não seja percebida ainda como o início de uma mudança, começa a infiltrar novos significados junto ao complexo sentido de impossibilidade e vergonha vivido pela cliente.

Alguns pontos chamam a atenção no tocante ao acolhimento necessário desse tipo de experiência. Primeiramente, é importante que o psicoterapeuta aprenda a reconhecê-la em sua especificidade como uma possibilidade presente, mas não obrigatória, dos clientes que procuram sua ajuda. Isso não deve significar que ele fique numa postura obsessiva à sua procura, mas apenas crie condições para que possa surgir, principalmente caso esteja relacionada às demandas do sujeito. Assim, um transe mediúnico, um ritual católico ou mesmo uma oração não necessariamente estão envolvidos com a experiência sagrada, porque podem consistir em práticas mecânicas configuradas muito mais com as trocas sociais de seus contextos do que com uma receptividade do sujeito para um encontro com o divino. Na experiência do sagrado existe algo que não se define, talvez por ser de uma esfera irracional como diria Otto (1917/2007) e mesmo assim é pleno de um poder organizador capaz de gerar um impacto profundo na vida do sujeito. Esse algo além, associado ao sentimento de divino (James, 1902/1987), arrebata o sujeito em uma sensação de paz que parece transportá-lo para outro lugar de onde, por vezes, sai renovado. No relato de Mariana, tal experiência se mostrou da seguinte forma: ao invés de julgada, como esperava, ela se sentia acolhida e protegida por essa força maior que parecia deitá-la numa outra esfera de onde poderia apreciar confortavelmente a pequenez dos problemas e preocupações cotidianos, resultando em modificações significativas em seu corpo (relaxamento e sono, antes difíceis), como nas configurações de seus problemas. É interessante observar que no instante em que a experiência se deu, a cliente ainda não pareceu estar muito consciente dos possíveis rumos que seu processo tomaria, mas apenas se regozijou com o alívio que ela lhe proporcionou. Porém, esse relato contém sugestões de mudanças bastante significativas que possuíram profundo impacto posterior em seu processo de mudança, como: a de que era possível conseguir contato com o sagrado, apesar dos conflitos e da vergonha; que era possível receber de seu mentor amparo e compreensão; de que ela poderia aprender a valorizar o que realmente merece ser valorizado (isto é, sua espiritualidade), vendo as coisas por um outro ângulo. Embora Mariana ainda não percebesse, tal experiência fazia um apelo a uma série de recursos e processos arraigados em sua história e subjetividade (crenças, práticas e sua missão espiritual) com as quais ela necessitava desenvolver uma espécie de reconciliação para resolver seus problemas.

$\mathrm{Na}$ perspectiva aqui adotada, considera-se que o psicoterapeuta entra em contato com esse universo encantado e, de certa forma, absoluto, habitado por deuses e seres espirituais e pode passar a ter uma ideia mais precisa sobre como eles atuam, transformam e se relacionam com a vida de seu cliente (Akstein, 1972; Erickson \& Rossi, 1979; Nathan, 1999). Concebendo o lugar desses personagens e poderes, como de suas implicações emocionais na vida do sujeito, o psicoterapeuta pode tanto construir seus próprios sentidos sobre o sagrado, a partir de seus marcos teóricos e experiência, como desenvolver a postura de aceitação e sensibilidade tão reclamada por clientes que possuem vivência religiosa. Tal postura não implica em dissolver as referências teóricas do psicoterapeuta nas crenças do cliente (o que seria a eliminação da psicoterapia), mas numa atitude pragmática em que a teoria trabalha na articulação dos processos que se originam a partir da experiência do sagrado.

\section{Construindo o contexto terapêutico}

Diante do exposto, um problema de ordem clínica se pôs de forma incontornável no processo terapêutico 
de Mariana. A experiência com seu mentor havia desencadeado possibilidades de mudança significativas e precisavam ser acolhidas para que tivessem continuidade em termos de eficácia. Ao mesmo tempo em que era importante que ela acreditasse que algo novo estivesse acontecendo, era necessário que o autor reconhecesse e qualificasse os recursos e processos por ela evocados em termos do potencial terapêutico que possuíam. Entretanto, neste ponto há uma dificuldade bastante comum no tocante ao uso das técnicas e do próprio papel do psicoterapeuta. Não é incomum que, em diferentes demandas clínicas, uma tendência à universalização do setting terapêutico impeça que o sujeito o adentre com seus sentidos legítimos que acabam sendo substituídos por narrativas consagradas numa determinada comunidade de psicoterapia (Gergen \& Kaye, 1998). É assim que, grosso modo, o conflito conjugal motivado por razões financeiras pode se transformar num conflito edípico mal resolvido com a mãe ou a depressão por causa do desemprego passa a ser concebida como fruto de uma opressão do mundo social. Já no que se refere às demandas ligadas à experiência religiosa, existe ainda outra faceta do problema em que o psicoterapeuta se mostra receoso e hesitante para lidar com esse universo, como se algum diálogo com o mesmo pudesse tirá-lo do papel de terapeuta e liga-lo ao papel de xamã ou líder espiritual. Nesse sentido, Aponte (1996) relata a curiosa situação em que líderes religiosos encaminham certas demandas à psicoterapia, ao mesmo tempo em que psicoterapeutas encaminham as mesmas demandas a uma ajuda religiosa sem assumir algum acompanhamento ou psicoterapia para essas pessoas. Não raro os psicoterapeutas demonstram constrangimento e mal estar diante de práticas espirituais, ora não sabendo como aproveitalas a favor do processo terapêutico, ora substituindo-as pelas técnicas tradicionais da psicoterapia, pois estas já são conhecidas, respaldadas e pretensamente superiores, sendo que sua utilização garante que permaneçam como psicoterapeutas e não sejam confundidos com feiticeiros.

Apesar dos dilemas existentes na psicologia como ciência e profissão (Figueiredo, 1996), a postura rígida e estreita com que tradicionalmente o tema da religião tem sido tratado na psicoterapia leva o psicoterapeuta a ser bastante seletivo quanto aos processos do sujeito, a uma postura de exclusão quanto à subjetividade do mesmo que pode até comprometer o andamento do processo terapêutico. Face a esse dilema, algumas considerações se fazem necessárias, já que o psicoterapeuta não deve abdicar de seu papel para que a terapia aconteça, mas também não deve excluir as possibilidades terapêuticas trazidas pelo cliente. Em primeiro lugar, além de um questionamento intenso sobre a liturgia técnica, com a concomitante possibilidade de diversificação de recursos técnicos, o psicoterapeuta deve estar centrado na reconstrução de sentidos do sujeito. Ele deve criar estratégias para que o cliente retorne a seu próprio universo (seus recursos subjetivos internos e sociais, suas práticas, suas crenças, sua rede social) e dali reconstrua suas configurações de sentido subjetivo. Como boa parte do sofrimento subjetivo encontra-se ligado a relações internas e externas da subjetividade do cliente, ele assume temporariamente a condição de um perturbador, um agente que produz desorganizações nos sistemas de crença e trocas sociais do cliente, para que novas relações surjam nesses sistemas e as soluções sejam criadas. O papel de orientador espiritual, de guia, padre, pai-de-santo deve, portanto, ser assumido por alguém da rede social do cliente, de maneira que, caso seja necessário, o psicoterapeuta deva trabalhar para que ele encontre alguém que possa assumir esse papel (Nathan, 1999).

Nessa condição, o psicoterapeuta pode mergulhar no universo do sujeito e a partir daí utilizar seus recursos a favor do processo de mudança (Erickson, 1952; Erikcson \& Rossi, 1979). Tendo consciência de que é um agente estranho, ele sabe que entrará nesse mundo temporariamente e, com algumas ações pontuais, provocará mudanças na relação do sujeito com deuses, seres espirituais, poderes, crenças e outros atores sociais para que o próprio sistema novamente se reorganize. Ao mesmo tempo, ele precisa reconhecer esses personagens e poderes, contata-los, negociar com eles e, se possível, utilizar sua participação a favor da terapia (Akstein, 1972; Richepport, 1994). Assim, ele não deve prescrever a comunhão para o sujeito a fim de que seja um bom católico, mas pode prescrevê-la, como na prescrição de tarefas (De Shazer, 1989) para que ele mesmo examine como está o sentido de sua fé no catolicismo; ele não deve se propor a realizar a desobsessão espírita em seu consultório, mas pode propor uma dramatização para que o próprio sujeito observe e represente como estão suas relações com os espíritos e com as pessoas de sua rede (Neubern, 2004); ele não deve pretender converter um sujeito a uma dada religião, mas pode, se existe alguma demande nesse sentido, prescrever que busque conhecer alguma que dê sentido a sua vida; ele não pode propor um ritual de oração para que cumpra uma obrigação espiritual, mas o pode propor a fim de que esse desencadeie processos terapêticos que o sujeito frequen- 
temente desconhece, mas podem ser importantes para sua psicoterapia. Portanto, ele pode estimular, provocar e colocar o sujeito em contato com a riqueza de processos subjetivos trazida pela experiência religiosa, que possui seus próprios aparatos técnicos.

Nesse sentido, o momento mais decisivo da psicoterapia de Mariana nasceu, efetivamente, do impasse que vivia: ela não conseguia escolher uma das opções que eram, em si mesmas, incompatíveis no seu sistema de crenças. Sua missão espiritual não poderia conviver com a desorganização de sua sexualidade compulsiva e com todos os sentidos de culpa, humilhação e vergonha que lhe causavam. Então, ela se dirigiu ao autor alegando que havia chegado o momento de fazer uma opção por sua missão espiritual, pois até o momento, a despeito de vez por outra sentir algum alívio, sentia que seu sofrimento era intenso e sua situação não havia se alterado significativamente. Face a esse pedido, profundamente permeado por intensidade emocional, o autor percebeu que era o momento de utilizar suas experiências com o sagrado como uma alavanca poderosa para a mudança, sobretudo, devido ao espaço privilegiado que a mesma ocupava na vida da cliente. Isso ocorreria de duas formas: primeiramente como um recontrato, como uma forma de reconciliação com essa potência, uma nova forma de se relacionar com ela; e, baseando-se nessa experiência, uma série de medidas que visassem romper com os padrões da compulsão sexual. Seguindo o pensamento de certos autores, como quanto à compulsão sexual (Neubern, 2004) e ao alcoolismo (Frankl, 1988), o autor colocava a experiência com sagrado como o pivô de uma reconstrução de vários processos de sua vida, como também como um modo de romper com os padrões compulsivos que se impunham à cliente.

Desse modo, para que o recontrato fosse efetivo, $o$ autor sabia que era necessário que a cliente se colocasse disponível subjetivamente para o mesmo, isto é, disponível para um processo de mudança profundo em sua vida que lhe exigiria muito empenho. Disse-lhe, então, que ela estava presa a um dilema com forças muito poderosas - a sexualidade e a espiritualidade e que, por isso, precisaria de uma terapia de choque para que seu pedido pudesse ser atendido. Caso ela estivesse disponível para tanto, deveria voltar dali a três dias e aceitar o que quer que fosse proposto pelo autor. Mesmo dizendo já aceitar a proposta naquele momento, o autor a dispensou e pediu que pensasse, voltando apenas no terceiro dia. Na data marcada, ele lhe propôs um transe hipnótico (Erickson, 1952), procedimento que lhe era familiar e útil, e sugeriu que ela visse as pessoas importantes de sua vida e que com cada uma delas falasse o que sentia sobre seu conflito e o que se propunha em termos de mudança. Uma a uma surgiram figuras de sua rede da maior importância, como seu pai, sua mãe, sua filha, seu dirigente no centro e, por fim, Frei Giuseppe. Diante da primeira figura, sua filha, desatou em lágrimas e disse que aquilo era muito difícil de fazer; mas, em seguida, ela pôde cumprir com o procedimento de maneira que, diante de cada figura, ela firmou o compromisso de levar adiante sua missão espiritual e abandonar seus comportamentos sexuais compulsivos. E, diante da visão de Frei Giuseppe, relatou:

Ele está em minha frente, sorrindo, como sempre. Ouve-me com atenção e diz que há muito tempo esperava por essa decisão (...) diz também que sempre tive ajuda e não é agora que a ajuda vai faltar. Agora é engraçado (...) me vejo criança indo para seu colo (...) ele me abraça e acaricia meus cabelos (...) sinto uma paz muito grande de novo (lágrimas) é alguma coisa muito especial (...) ele diz que podemos contar com ele.

Semelhante acontecimento, longe de ter consistido em uma etapa mecânica de um processo terapêutico, consistiu numa espécie de divisor de águas para Mariana, como também para seu psicoterapeuta. Construído artesanalmente e considerando, sobretudo, o sentido da mediunidade na vida da cliente - uma missão espiritual - este momento significou para ela um renascimento em termos do compromisso com essa missão e, consequentemente, com uma série de reformulações exigidas por ela. Aqui, dois pontos merecem destaque. Por um lado, o impacto da experiência foi possível devido a um procedimento muito semelhante ao batismo ou à conversão cristã primitiva, nos quais o sujeito confessava seus pecados em público, submetia-se ao ritual e assumia uma nova postura, às vezes até com mudança de nome. Mesmo que se tratasse de uma situação imaginária criada pela hipnose, Mariana, talvez pela primeira vez, pôde assumir abertamente seus problemas de ordem sexual diante das pessoas significativas em sua vida e se comprometer com elas a adotar uma postura de vida mais condizente com o que, para ela, era certo. Isso permitiu com que ela saísse de seu isolamento, pois quando estava vivenciando seus problemas procurava cortar qualquer conexão com os outros, e amplificasse esse canal emocional com pessoas que possuíam um grande valor em sua vida e poderiam fornecer importantes recursos para seu processo de mudança. Mesmo que tais pessoas não tivessem sido conscientemente envolvidas, elas já 
faziam parte do problema de Mariana e agora poderiam ajudar na construção das soluções.

O segundo ponto, profundamente integrado ao primeiro, refere-se à reconciliação com uma dimensão muito importante de sua vida - sua missão espiritual. Mariana sentia um conflito profundo nos últimos anos, já que desde pequena ouvia falar de uma missão espiritual a ser cumprida com sua mediunidade, o que não era compatível com o que ela mesmo denominava "desatinos sexuais". Havia, portanto, uma dimensão de sua vida com a qual não se relacionava bem, uma dimensão que era importante e que ocupava um lugar privilegiado, mas com quem não conseguia se conectar sem conflito, já que o desejo sexual a levava numa direção antagônica. É bastante significativo que Frei Giuseppe tenha sido a última visão de Mariana: após passar sua vida à limpo frente a importantes testemunhas de sua rede social, chamadas pelo autor como 'fiadores', surge o representante do sagrado, aquele que a inseria no universo daquela experiência além das palavras. Mas o que é mais significativo para o processo é que, essa experiência sempre ocorria há muito tempo, mas numa condição em que a cliente recebia seus benefícios e sua influência, mas não conseguia se sentir no direito de pertencer a ela. Agora, era ela, Mariana, quem a procurava, com a disponibilidade de situá-la no lugar que lhe era devido e a possibilidade de se sentir pertencendo a essa missão maior de uma forma mais inteira e plena. É curioso notar que após ter visto sua própria imagem como uma menina sendo acolhida pela figura de seu mentor, a cliente relatou várias lembranças em que o bondoso frei cuidava dela quando criança, como se pudesse fazer uma revisão do lugar dessa figura em sua vida.

Com efeito, a construção de um contexto terapêutico junto a clientes que possuem experiências religiosas exige que se o cliente as elege em sua vida como uma dimensão central, essa dimensão deve também ser reconhecida em sua importância pelo psicoterapeuta que, dentro de seu papel profissional e sua condição pessoal, pode fazer dela um instrumento poderoso de mudança. Após esse episódio, Mariana pôs fim a seus "desatinos sexuais", mas também continuou com seus problemas cotidianos quanto à sua família, sua menina, seu trabalho, de maneira a não deixar de se mostrar irritadiça quanto aos procedimentos que evitavam o domínio do impulso sexual ${ }^{7}$, precisando de grande esforço para cumprir com os mesmos. Porém, o constante trabalho por meio da auto-hipnose, incentivado por sua psicoterapia, ou dos transes em seu centro espírita lhe supriam as condições para que pudesse lidar com seus problemas, com seu projeto espiritual (sua missão) como também abrir outras perspectivas de sentido para sua própria vida. Como essa dimensão havia sido reconhecida e valorizada, a psicoterapia se constituiu num espaço onde Mariana poderia reconstruir sentidos em sua vida, ocupar novas posições em seus campos de ação social e superar seu dilema.

\section{CONSIDERAÇÕES FINAIS: SENTIDO E RECONHECIMENTO}

Há circunstâncias e acontecimentos da experiência religiosa diante dos quais faltam palavras à ciência, seja devido a sua complexidade, seja por se tratar de uma alçada que não é do escopo deste ramo do saber (Morin, 1991). Quando ocorrem, realmente, não resta nada a dizer no sentido de buscar explicá-los dentro de uma racionalidade moderna, já que o conhecimento científico e, mais especificamente, psicológico possui seus limites e é importante que o psicoterapeuta tenha noção deles sob a pena de comprometer seu trabalho. Entretanto, apesar de não ser possível tal empreitada, é possível dialogar com os sujeitos de maneira a conhecer as realidades, isto é, construção de sentidos, que se criam na subjetividade a partir dessas experiências (James, 1902/1987). Aqui, certamente, o psicólogo tem algo a dizer e o psicoterapeuta a propor quando o sujeito lhe traz alguma demanda que é perpassada por experiências religiosas e, mais ainda, sagradas. É necessário, portanto, um reconhecimento da experiência religiosa como um campo à parte, específico e com características próprias que, mesmo escapando ao alcance explicativo e racional (Otto, 1917/2007), é um foco gerador de sentidos fundamentais na vida de muitas pessoas.

Explicar o que seria a figura de Frei Giuseppe não era o importante para Mariana que estava muito mais preocupada com os sentimentos de vergonha que sentia diante dele quanto a seus comportamentos sexuais. Caso o autor não reconhecesse tais configurações e suas implicações na vida da cliente, seria impossível estabelecer um processo terapêutico calcado na compreensão de seus sentidos e no diálogo a partir dos mesmos (Anderson, 1997; Erickson \& Rossi, 1979; Gonzalez Rey, 2007). Dito de outro modo, o diálogo não consiste em mera troca de palavras, mas numa postura que se dispõe, de fato, a reconhecer e considerar o que se passa com o outro no seu mundo singular, o papel que ele ocupa nesse mundo, as histórias aí presentes e os seres com quem ele interage, por mais que isso parece bizarro, distante ou irracional. Uma consideração assim profunda por esse outro aí presente 
permite ao psicoterapeuta entrar em contato com a experiência do sagrado procurando saber sempre um pouco mais sobre como ela é situada pelo sujeito, ao contrário do medo que a exclui da conversação ou a reduz a algum lugar que é seguro, mas distante e improdutivo. Talvez apenas aí, o psicoterapeuta possua uma autoridade para conceber o que são os sentidos do cliente, uma vez que foi apresentado pelo próprio a este mundo de tanta riqueza e complexidade.

Por fim, cabe destacar um aspecto importante no que se refere à dimensão técnica, comumente concebida como ferramenta exclusiva do psicoterapeuta que a adquiriu por sua condição de especialista. $\mathrm{O}$ que aqui foi levantado foi que as pessoas que possuem experiências religiosas frequentemente são dotadas de grandes possibilidades de recursos pessoais e sociais, que podem ser considerados como uma forma distinta de técnica (Akstein, 1972; Erickson, 1958; Nathan, 1999), como foi o caso da prece e do transe utilizados por Mariana. À medida que o terapeuta se aprofunda no sistema de crenças e práticas sociais do sujeito, como em suas construções de sentido, ele percebe que pode desencadear mudanças significativas por meio de uma diversidade de recursos que o sujeito já dispõe, mas talvez ainda não tenha criado condições para aproveitá-lo melhor ou mesmo atribuir-lhes outro valor. É assim que se torna possível ao terapeuta possibilitar a mudança por meio de suas próprias técnicas do sujeito, que as conhece profundamente, as partilha em sua rede social e se não possui a maestria necessária para utilizá-la da forma correta, dispõe de alguém em suas relações que possa cumprir esse papel. Neste caso, é importante que o terapeuta esteja imbuído da ideia de que ele não se torna o especialista daquela cultura particular, mas o provocador externo que não abre mão de manter sua proposta de psicoterapia.

\section{REFERÊNCIAS}

Akstein, D. (1972). Hipnologia. Rio de Janeiro: Hypnos.

Andersen, T. (1996). Processos reflexivos (R. Bergallo, Trad.). Rio de Janeiro: Noos.

Anderson, H. (1997). Conversation, language and possibilities. New York: Basic Books.

Anderson, H., \& Goolishian, H. (1998). O cliente é o especialista. Em S. McNamme \& K. Gergen (Orgs.), A terapia como construção social (C. Dornelles, Trad.) (pp. 22-35). Porto Alegre: Artmed.

Aponte, H. (1996). El sesgo político, los valores morales y la espiritualidad en la formación de los psicoterapeutas. Sistemas Familiares, 10, 9-19.

Aurobindo, S. (1970). The life divine. Pondicherry, India: Sri Aurobindo Ashram Press. (Original publicado em 1939)
Carvalho, J. (1994). O encontro de novas e velhas religiões: Esboço de uma teoria dos estilos de espiritualidade. Em A. Moreira \& R. Zicnan (Orgs.), Misticismo e novas religióes (pp. 67-98). Petrópolis: Vozes.

Cerqueira-Santos, E., Koller, S., \& Pereira, M. (2004). Religião, saúde e cura: Um estudo entre neopentecostais. Psicologia: $\mathrm{Ci}$ ência e Profissão, 3, 82-91.

D’Avila, S. T. (1964). Oeuvres completes. Paris: Desclée de Brouwer. (Obras originais publicadas no século XVI)

De Shazer, S. (1989). Pautas de terapia familiar breve. Barcelona: Paidós.

Demo, P. (2000). Saber pensar. São Paulo: Cortez.

Eliade, M. (1969). Le mythe de l'eternel retour. Paris: Gallimard.

Eliade, M. (1965). Le sacré et le profane. Paris: Gallimard.

Erickson, M. (1952). Deep hypnosis and its induction. Em L. LeCron, Experimental hypnosis (pp. 70-114). New York: Macmillan.

Erickson, M. H. (1958). Naturalistic techniques of hypnosis. American Journal of Clinical Hypnosis, 1, 3-8.

Erickson, M., \& Rossi, E. (1979). Hypnotherapy: An exploratory casebook. New York: Irvington.

Figueiredo, L. C. (1996). Revisitando as psicologias. Petrópolis: Vozes.

Frankl, V. (1988). The will to meaning. New York: Meridian.

Freud, S. (1997). O futuro de uma ilusão. (J. Aguiar Abreu, Trad.). Rio de Janeiro: Imago. (Original publicado em 1927)

Gergen, K. \& Kaye, J. (1998). Além da narrativa na negociação do sentido terapêutico. Em S. McNamme \& K. Gergen (Orgs.). A terapia como construção social (C. Dornelles, Trad.) (pp. 201222). Porto Alegre: Artes Médicas. (Original publicado em 1995)

Gonzalez Rey, F. (2005). O social na psicologia e a psicologia social. Petrópolis: Vozes.

Gonzalez Rey, F. (2007). Psicoterapia, subjetividade e pósmodernidade. São Paulo: Thomsom.

Hacking. I. (2001). L'âme réécrite: Personnalité multiples et sciences de la mémoire. Paris: Seuil.

James, W. (1987). The varieties of religious experience. Em B. Kuklick (Org.), William James: Writtings 1902-1910 (pp. 1477). New York: Literary Classics of the United States. (Original publicado em 1902)

João da Cruz, S. (1972). Obras completas. Petrópolis: Vozes. (Obras originais publicadas no século XVI)

Lax, W. (1997). Narrativa, construccionismo social y budismo. Em M. Pakman (Org.), Construcciones de la experiencia humana (pp. 147-171). Barcelona: Gedisa.

Méheust, B. (1999). Somnambulisme et médiumnité. Paris: Seuil.

Mijola, A. (1981). Les visiteurs du moi: Fantasmes d'identification. Paris: Les Belles Lettres.

Morin, E. (1991). La méthode IV: Les idées. Paris: Seuil.

Morin, E. (1994). Mes démons. Paris: Sock.

Natan, T. (1999). Manifeste pour une psychopathologie scientifique. Em T. Natan \& I. Stengers (Orgs.), Médecins et sorciers (pp. 9-113). Paris: Synthelabo.

Neubern, M. (2004). Complexidade e psicologia clínica: Desafios epistemológicos. Brasília: Plano. 
Neubern, M. (2005). A dimensão regulatória da psicologia clínica: $\mathrm{O}$ impacto da racionalidade dominante nas relações terapêuticas. Estudos de Psicologia, 10, 73-82.

Neubern, M. (2009). Psicologia, hipnose e subjetividade: Revisitando a história. Belo Horizonte: Diamante.

Otto, R. (2007). O sagrado (W. Schlupp, Trad.). Petrópolis: Vozes. (Original publicado em 1917)

Quintana, A. (1999). A ciência da benzedura. Bauru: EDUSC.

Richeport, M. (1994). Erickson's approach to multiple personality: A cross-cultural perspective. Em J. Zeig (Org.), Ericksonian methods (pp. 415-432). Levittown, PA: Brunner/Mazel.
Rose, S. (2006). O cérebro do século XXI (H. Londres, Trad.). Rio de Janeiro: Globo.

Santos, B. S. (2000). A crítica da razão indolente. São Paulo: Cortez.

Stengers, I. (2001). Qu'est-ce que l'hypnose nous oblige à penser? Ethnopsy: Les Monde Contemporain de la Guerison, 3, 13-68.

Recebido: 03/08/2009

Última revisão: 26/04/2010

Aceite final: 03/05/2010

\section{Notas:}

1 Este artigo é fruto de projeto de pesquisa do autor, intitulado "Subjetividade, Dor e Hipnose: A Construção do Contexto Terapêutico", financiado pelo Centro Universitário de Brasília (UniCeub) e registrado no CONEP (Conselho Nacional de Ética em Pesquisa) do Ministério da Saúde.

2 O termo experiência religiosa será tomado aqui como a subjetivação de vários processos que a compõem em sua complexidade: sociais, culturais, institucionais, econômicos, etc. Dentre esses processos há também a experiência do sagrado (Otto, 1917/2007), que se refere à vivência daquilo que é considerado sagrado ou divino pelo sujeito em seu sistema de crenças.

3 A maior parte das experiências dessa natureza são temporárias, sendo que uma constância ou permanência maior parece ser restrita a pessoas, como Santos e Yogues, que se dedicam integralmente a elas. Os exemplos de Santa Teresa d'Avila (1964), São João da Cruz (1972) e Sri Aurobindo (1970) são bastante ilustrativos. Embora possa ser provocado como no exemplo clínico aqui discutido, tal experiência não pode ser reduzida a mero estado hipnótico, uma vez que o contexto simbólico desses processos é consideravelmente distinto (Stengers, 2001).

4 Durante o processo de subjetivação do sujeito, em sua dialética com o mundo social, ele integra, na forma de configurações, processos emocionais e simbólicos. A qualidade dominante que daí emerge chama-se sentido subjetivo (Gonzalez Rey, 2007) e é perpassada por ampla complexidade de dimensões sociais e culturais.

5 Semelhante reducionismo, profundamente influenciado pelo legado freudiano (Freud, 1927/1997), pode ser considerado dentro de uma perspectiva histórica nos confrontos entre ciência e religião no ocidente e as consequências dessa batalha no nascimento da psicologia (Méheust, 1999; Neubern, 2009).

6 Seu sistema de crenças permite a comparação com os sistemas estudados por Tobie Nathan (1999) que sempre incluem o lugar do outro nos dramas da vida do sujeito e rompem com a perspectiva solitária dos sistemas modernos, onde a causalidade está associada a alguma entidade impessoal, como a genética, o cérebro ou a psique.

7 Tais instruções, respeitando seu sistema de crenças, foram desenvolvidas de acordo com alguns autores já citados (Erickson \& Rossi, 1979; Neubern, 2004), mas não foi possível descrevê-las melhor devido aos limites de espaço deste trabalho.

\section{Sobre o autor:}

Maurício da Silva Neubern: Psicólogo, Doutor em Psicologia pela Universidade de Brasília (2003), Professor Adjunto do Departamento de Psicologia Clínica, Instituto de Psicologia (UnB).

Endereço para correspondência: Campus Universitário Darcy Ribeiro - ICC - Sul - Departamento de Psicologia Clínica - Instituto de Psicologia - 70910-900 Brasília/DF. Endereço eletrônico: mneubern@ hotmail.com. 